Applied Remote Sensing

\title{
Using long time series of Landsat data to monitor impervious surface dynamics: a case study in the Zhoushan Islands
}

Xiaoping Zhang

Delu Pan

Jianyu Chen

Yuanzeng Zhan

Zhihua Mao 


\title{
Using long time series of Landsat data to monitor impervious surface dynamics: a case study in the Zhoushan Islands
}

\author{
Xiaoping Zhang, ${ }^{\mathrm{a}, \mathrm{b}}$ Delu Pan, ${ }^{\mathrm{a}, \mathrm{b}}$ Jianyu Chen, ${ }^{\mathrm{b}}$ Yuanzeng Zhan, ${ }^{\mathrm{c}}$ and \\ Zhihua Maob \\ ${ }^{a}$ Wuhan University, State Key Laboratory for Information Engineering in Surveying, \\ Mapping and Remote Sensing, Wuhan 430079, China \\ chenjianyu@sio.org.cn, pandelu@sio.org.cn \\ ${ }^{\mathrm{b}}$ State Oceanic Administration, Second Institute of Oceanography, State Key Laboratory of \\ Satellite Ocean Environment Dynamics, 36 Baochubei Road, Hangzhou 310012, China \\ ${ }^{\mathrm{c}}$ Geomatics Center of Zhejiang, Hangzhou 310012, China
}

\begin{abstract}
Islands are an important part of the marine ecosystem. Increasing impervious surfaces in the Zhoushan Islands due to new development and increased population have an ecological impact on the runoff and water quality. Based on time-series classification and the complement of vegetation fraction in urban regions, Landsat thematic mapper and other high-resolution satellite images were applied to monitor the dynamics of impervious surface area (ISA) in the Zhoushan Islands from 1986 to 2011. Landsat-derived ISA results were validated by the high-resolution Worldview-2 and aerial photographs. The validation shows that mean relative errors of these ISA maps are $<15 \%$. The results reveal that the ISA in the Zhoushan Islands increased from $19.2 \mathrm{~km}^{2}$ in 1986 to $86.5 \mathrm{~km}^{2}$ in 2011, and the period from 2006 to 2011 had the fastest expansion rate of $5.59 \mathrm{~km}^{2}$ per year. The major land conversions to high densities of ISA were from the tidal zone and arable lands. The expansions of ISA were unevenly distributed and most of them were located along the periphery of these islands. Time-series maps revealed that ISA expansions happened continuously over the last 25 years. Our analysis indicated that the policy and the topography were the dominant factors controlling the spatial patterns of ISA and its expansions in the Zhoushan Islands. With continuous urbanization processes, the rapid ISA expansions may not be stopped in the near feature. (C) The Authors. Published by SPIE under a Creative Commons Attribution 3.0 Unported License. Distribution or reproduction of this work in whole or in part requires full attribution of the original publication, including its DOI. [DOI: 10.1117/1.JRS.7.073515]
\end{abstract}

Keywords: impervious surface; island; time series; land use/land cover; remote sensing.

Paper 12312 received Sep. 18, 2012; revised manuscript received Jul. 16, 2013; accepted for publication Jul. 19, 2013; published online Aug. 28, 2013.

\section{Introduction}

Coastal islands are located in a transitional environment where land and ocean interact. Such an environment is vulnerable to human activities due to limited natural resources. Under urbanization and intensive exploitation activities, the coastal zone ecosystem health in Zhejiang province is facing serious threats. ${ }^{1}$ During the past 20 years, large areas of natural landscape of the Zhoushan Islands have been increasingly replaced by impervious surfaces. Impervious surface area (ISA) can be defined as any material that prevents the infiltration of water into the soil, such as paved roads, driveways, parking lots, buildings, rooftops, and so on. ${ }^{2}$ The expansion of impervious surfaces can affect the hydrological cycle, water quality, local climate, and biodiversity. ${ }^{3}$ It was found that most stream quality declines if $>10 \%$ area of a watershed is impervious. ${ }^{4}$ Quantification of impervious surfaces in landscape has become increasingly important with growing concern of its impact on the environment. ${ }^{5-8}$

Remote sensing has long been used for land use/land cover (LULC) classification, and it allows up-to-date, spatially explicit estimates of urban surface imperviousness over large areas. ${ }^{9-11}$ Ridd proposed the classic vegetation-impervious surface-soil model to parameterize biophysical composition of urban environments. ${ }^{12}$ Carlson and Arthur retrieved the fraction 
impervious surface of Chester Country based on the inverse relationship between impervious surfaces and vegetation. ${ }^{2} \mathrm{Wu}$ and Murray estimated impervious surface distribution of the metropolitan area of Columbus, Ohio, through a fully constrained linear spectral mixture model. ${ }^{13}$ Xian and Crane determined impervious surfaces of the Tampa Bay watershed in Florida, to assess urban sprawling, using a regression tree algorithm. ${ }^{14}$ Object-based image analysis has been increasingly used to map impervious surfaces due to the advent of high-resolution satellite imagery. ${ }^{15-17} \mathrm{Xu}$ proposed a novel index, normalized difference impervious surface index (NDISI), to estimate impervious surfaces of Fuzhou City with a high degree of automation compared to the majority of the present methods. ${ }^{18}$ To sum up, the methods for mapping ISA with remote sensing technology can be classified into four groups: visual interpretation or multispectral classification, complement of vegetation fraction, spectral mixture analysis, and band combination method. Previously mentioned studies were mostly applied to inland regions and they might not be suitable for islands. For islands, in addition to types of woodland, arable land, urban or built-up areas, rural settlements, and water bodies, there are also brine pan, tidal zone, and aquaculture, the spectral curves of which can easily be confused with impervious surfaces under the influence of water. ${ }^{19,20}$ Zhou and Wang developed a multiple agent segmentation and classification algorithm that included the steps of a multiple agent segmentation, shadow-effect, multivariate analysis of variance-based classification, and postclassification to extract ISA maps in the state of Rhode Island, USA, using Quickbird-2 imagery. Besides, many researchers have done some work in island land-cover analysis using remote sensing and geographic information system. ${ }^{21-25}$ Chen et al. explored the temporal composition and spatial configuration of the land-cover trajectories in the ZS and its surrounding islands from 1986 to 2000, and revealed that the land cover had changed rapidly in the $\mathrm{ZS} .{ }^{23}$ However, little attention was paid to the evolution of island impervious surface over time, and long-term impervious surface mapping and change analysis in islands have not been conducted. Therefore, this study will take the Zhoushan Islands as a case study to map and analyze impervious surface dynamics over the past 25 years.

Choosing one or more end members to represent multiple impervious surfaces is not easy. This is particularly true for applying low- and medium-resolution remote sensing data. ${ }^{26}$ The construction of the NDISI needs thermal data, and therefore the remotely sensed data without thermal bands are useless in the indicator. Visual interpretation or multispectral classification is mainly applied to high-resolution imagery. Because of the inverse correlation between ISA and vegetation cover in urban areas, one potential approach for impervious surface extraction is through vegetation distribution. ${ }^{2,27-29}$ The methods for acquiring vegetation fractions from remote sensed data are quite mature following many years large-scale experiments. ${ }^{27-31}$ Here, we assume that within the urban (or developed) pixels, all areas without vegetation covers belong to ISA and ISA are only distributed in these urban (or developed) pixels. Therefore, mapping ISA needs two data sources: vegetation cover and urban distributions. Based on Chen's study, the newly developed areas in 1986, 1990, 1995, 2000, 2006, and 2011 can be acquired. ${ }^{23}$ Another parameter, fractional vegetation distribution, can be calculated by the scaled normalized difference vegetation index (NDVI) or tasseled cap transformation. ${ }^{28,32-34}$ Therefore, we decided to combine the time-series classification and fractional vegetation cover to map and monitor impervious surface dynamics of the Zhoushan Islands.

The objectives of this research are (1) to build time-series ISA maps in the study area, (2) to estimate ISA and its changes over different time periods, (3) to examine conversions between impervious surfaces and other LULC types, and (4) to analyze temporal and spatial variations of ISA distribution in the new urban areas.

\section{Study Area and Data}

\subsection{Study Area}

The study area is part of Dinghai District, Putuo District, and Daishan Country $\left(29^{\circ} 55^{\prime}-30^{\circ} 12^{\prime} \mathrm{N}\right.$, $\left.121^{\circ} 48^{\prime}-122^{\circ} 20^{\prime} \mathrm{E}\right)$ of Zhoushan archipelago new area, located in the northeast of Zhejiang province, China. It includes ZS and its surrounding inhabited islands, namely Jintang (JT), Xiushan (XS), Cezi (CZ), Changbai (CB), Changzhi (CHZ), Damao (DM), Aoshan, 


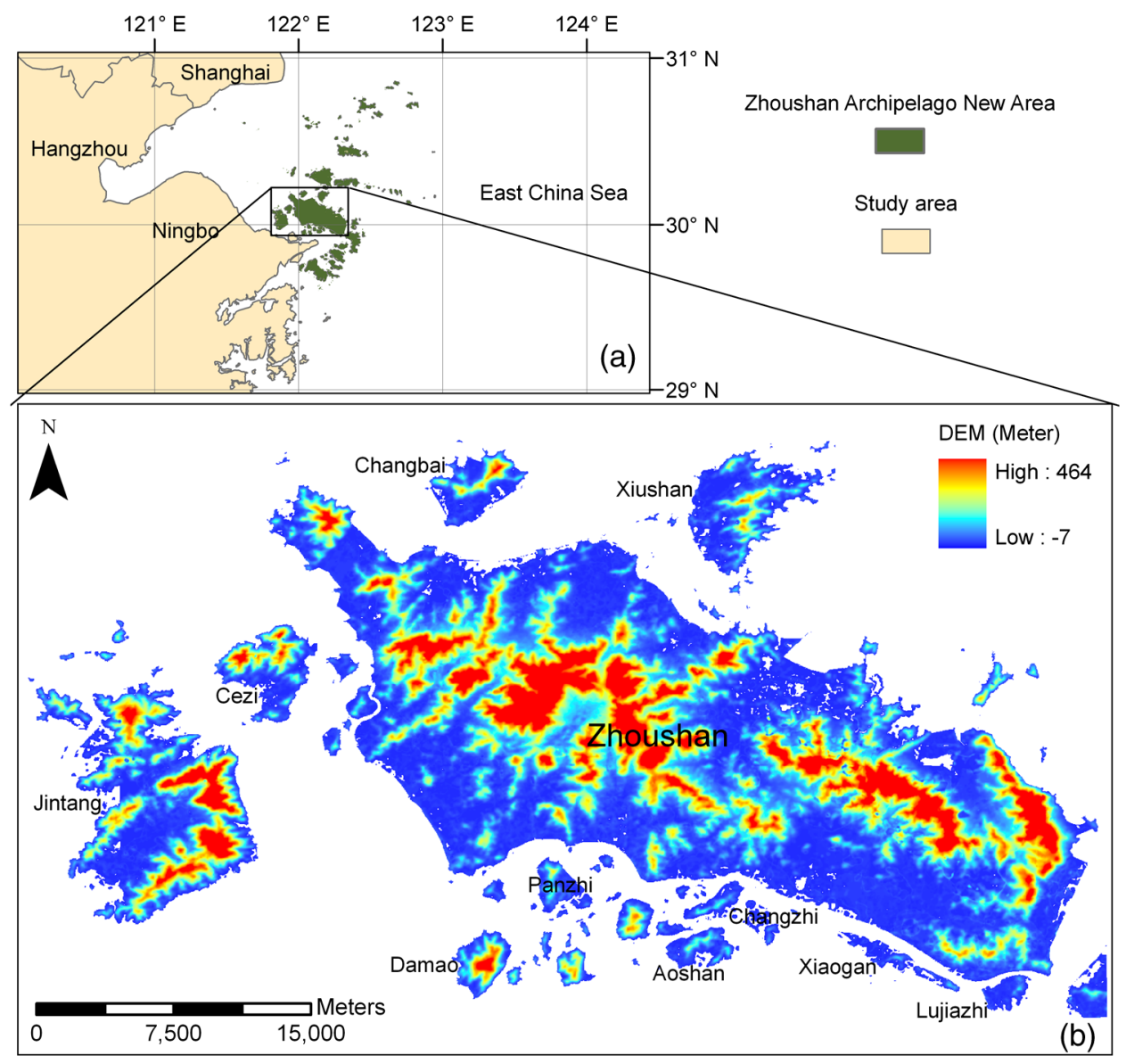

Fig. 1 (a) Location of the study area, which covers part of Zhoushan archipelago new area. (b) The digital elevation model (DEM) maps for the study area, -7 to 464 represents the values of DEM (unit: meter).

Xiaogan-mazhi (XG), Panzhi (PZ), and Lujiazhi (LJZ), covering an area of $\sim 703.34 \mathrm{~km}^{2}$ (Fig. 1). The basic information of these islands is listed in Table 1. The Zhoushan Islands have a hilly landscape and their climate belongs to the monsoon-influenced subtropical marine system. The mean annual temperature is around $17^{\circ} \mathrm{C}$, and the average annual rainfall is 1300 to $1500 \mathrm{~mm}$. Coniferous forests, evergreen broad-leaved forests, and deciduous broad-leaved forests are widely distributed on this archipelago. The capital, Zhoushan city, has been one of the pioneering cities in the Yangze River Delta area since 1988. With the Zhoushan cross-sea bridge between Zhoushan and Ningbo city, the study area is subject to rapid changes in transportation, ports, tourism, and fisheries. Economic prosperity in the Zhoushan Islands has generated a significant competition over limited land resources. Quantifying the ISA and analyzing impervious surface change during the past 25 years in the Zhoushan Islands are therefore of great importance to characterize the influence of anthropogenic activities in this area.

\subsection{Data and Preprocessing}

Remotely sensed data sets used in this study are listed in Table 2. The selected images were georeferenced into a common transverse mercator projection with geometric errors $<1$ pixel. Then the digital numbers of Landsat images were retrieved to apparent reflectance by using the model of Chander et al. ${ }^{35}$ The nearest-neighbor resampling technique was used to resample the images into a pixel size of $30 \mathrm{~m}$ by $30 \mathrm{~m}$ for Landsat images, $5 \mathrm{~m}$ by $5 \mathrm{~m}$ for SPOT5 multispectral images, and $0.5 \mathrm{~m}$ by $0.5 \mathrm{~m}$ for Worldview- 2 multispectral images. We used Pansharp fusion method from ENVI EX 4.8 to merge images of SPOT5 and Worldview-2.

CORONA images from the year 1970 were used to map early historical land cover over the study region. Landsat TM/ETM+ imagery and SPOT5 were used to quantify the LULC and 
Zhang et al.: Using long time series of Landsat data to monitor impervious surface dynamics...

Table 1 Introduction of the main islands in the study area.

\begin{tabular}{|c|c|c|c|c|}
\hline Island & Location & Area $\left(\mathrm{km}^{2}\right)$ & Distance $(\mathrm{km})$ & Function \\
\hline Zhoushan & & 503.84 & $\sim$ & Comprehensive development \\
\hline Jintang & & 81.11 & 29 & Comprehensive development \\
\hline Cezi & & 15.01 & 2.5 & Port logistics \\
\hline Changbai & Dinghai District & 13.32 & 1.1 & Urban extension \\
\hline Changzhi & & 7.51 & 0.3 & Urban extension and marine research \\
\hline Damao & & 6.6 & 2.6 & Port logistics \\
\hline Aoshan & & 5.15 & 2.7 & Port logistics \\
\hline Panzhi & & 4.23 & 0.9 & Ship repairing and building base \\
\hline Xiushan & Daishan Country & 25.47 & 2.5 & Marine tourism \\
\hline Xiaogan & Putuo District & 5.24 & 0.3 & Harbor industry \\
\hline Lujiazhi & & 3.77 & 0.2 & Urban extension \\
\hline
\end{tabular}

Note: The area was calculated in ArcMap based on the investigation map of 2005, including both land and tidal zone. The distance means the least distance from the Zhoushan island.

Table 2 Remotely sensed data used.

\begin{tabular}{|c|c|c|}
\hline Sensor data & Acquisition date & Spectral and spatial resolution \\
\hline CORONA & $\begin{array}{l}\text { March } 15,1970 \\
\text { May } 31,1986\end{array}$ & One panchromatic band with $1.83 \mathrm{~m}$ (resampled with $5 \mathrm{~m}$ ) \\
\hline & June 11,1990 & Three visible bands (blue, green, and red), one near-infrared (NIR) \\
\hline $\begin{array}{l}\text { Thematic } \\
\text { mapper (TM) }\end{array}$ & $\begin{array}{l}\text { August } 12,1995 \\
\text { June } 3,2006 \\
\text { May } 20,2011\end{array}$ & $\begin{array}{l}\text { Band and two shortwave infrared (SWIR) bands with } 30 \mathrm{~m} \text { spatial } \\
\text { Resolution }\end{array}$ \\
\hline ETM+ & June 14, 2000 & $\begin{array}{l}\text { The same as TM, but including one panchromatic band with } 15 \mathrm{~m} \\
\text { spatial resolution }\end{array}$ \\
\hline SPOT5 & April 20, 2011 & $\begin{array}{l}\text { Two visible bands (green, red), one NIR band, and one } \\
\text { SWIR band with } 10 \mathrm{~m} \text { spatial resolution, one } \\
\text { panchromatic band with } 2.5 \mathrm{~m}\end{array}$ \\
\hline Worldview-2 & April 23, 2010 & $\begin{array}{l}\text { Three visible bands (blue, green, and red), two NIR } \\
\text { bands, one coastal band, one yellow band, and one red edge band } \\
\text { with } 2.0 \mathrm{~m} \text { spatial resolution, one panchromatic band with } 0.5 \mathrm{~m} \\
\text { spatial resolution }\end{array}$ \\
\hline Aerial data $1^{a}$ & December, 1990 & $\begin{array}{l}\text { One panchromatic band with } 1 \mathrm{~m} \text { spatial resolution for the photograph } \\
\text { and scale of } 1: 10,000 \text { for corresponding digital raster graph (DRG) }\end{array}$ \\
\hline Aerial & October, 2002 & Three visible bands (blue, green, and red) with $1 \mathrm{~m}$ spatial resolution \\
\hline data $2^{b}$ & March, 2007 & Three visible bands (blue, green, and red) with $1 \mathrm{~m}$ spatial resolution \\
\hline
\end{tabular}

${ }^{\mathrm{a}}$ Aerial photograph and DRG.

${ }^{\mathrm{b}}$ Aerial data2: Aerial orthophotographs. 
Zhang et al.: Using long time series of Landsat data to monitor impervious surface dynamics...

Table 3 Accuracy assessment.

\begin{tabular}{llll}
\hline \hline Time & Validation data & Test area & Statistical indicators MRE/R \\
\hline 1990 & 1990 aerial photograph and & Dinghai & $0.144 / 0.583$ \\
& DRG & Putuo & $0.157 / 0.758$ \\
2000 & 2002 aerial orthophotograph & Dinghai & $0.108 / 0.601$ \\
& & Jintang & $0.131 / 0.608$ \\
2006 & 2007 aerial orthophotograph & Putuo & $0.090 / 0.612$ \\
& & Jintang & $0.085 / 0.595$ \\
2011 & 2010 Worldview-2 image & Dinghai & $0.085 / 0.621$ \\
& & Putuo & $0.070 / 0.606$ \\
\hline \hline
\end{tabular}

impervious surface change in the Zhoushan islands. The aerial photographs of 1990, 2002, and 2007, as well as Worldview-2 fused images in 2010, were combined for evaluating the extracted ISA maps (Table 3). Other data sets used in this study include differential global positioning system data and the land-use vector data from Zhejiang Administration of Surveying Mapping and Geoinformation, China; these are utilized as the reference data for classification purposes.

\section{Methodology}

\subsection{Estimating ISA}

ISA is generated by applying the following formulation. ${ }^{2,36}$ As mentioned earlier, we assume that ISAs are only distributed in pixels being classified as "developed" and it is the fraction of each pixel that is not covered by vegetation.

$$
\mathrm{ISA}=\left(1-F_{r}\right)_{\mathrm{dev}},
$$

where the subscript dev indicates that the quantity is defined only for pixels classified as "developed" (i.e., urban/suburban) and $F_{r}$ indicates fractional vegetation cover in a pixel.

\subsubsection{Fractional vegetation cover}

To obtain $F_{r}$, we first compute NDVI. NDVI is defined as

$$
\mathrm{NDVI}=\frac{\rho_{\text {nir }}-\rho_{r}}{\rho_{\text {nir }}+\rho_{r}},
$$

where $\rho_{r}$ is reflectance in the red band (630 to $690 \mathrm{~nm}$ ) and $\rho_{\text {nir }}$ is reflectance in the near-infrared band (760 to $900 \mathrm{~nm}$ ).

To remove biases from atmospheric influences on NDVI, we used two references, one for bare soil $\left(\mathrm{NDVI}_{s}\right)$ and one for full vegetation $\left(\mathrm{NDVI}_{v}\right)$, respectively, to rescale the calculated NDVI. ${ }^{33}$ The rescaled vegetation index $\left(N^{*}\right)$ is calculated as

$$
N^{*}=\frac{\mathrm{NDVI}-\mathrm{NDVI}_{s}}{\mathrm{NDVI}_{v}-\mathrm{NDVI}_{s}} .
$$

In this research, we overlaid NDVI maps for each time on the corresponding classification map to derive $\mathrm{NDVI}_{v}$ in the land type of "woodland" and $\mathrm{NDVI}_{s}$ in the land type of "dryland," respectively. Time-series classification maps are discussed in Sec. 3.1.2.

Field experiments and observations indicated that $F_{r}$ has a linear relationship with $N^{* 2}$ (Refs. 32, 36, and 37) and we used this equation to quantify $F_{r}$ from $N^{*}$.

$$
F_{r} \approx N^{* 2} \text {. }
$$




\subsection{2 "Developed" pixels}

The "developed" pixels were picked out from LULC maps which were classified with Landsat TM/ETM and other sources during 1986 to 2011. To decrease data gaps in historical periods and update recent changes in LULC, we generated three new time slots of LULC maps (i.e. 1990, 2006, and 2011) over our previous work, i.e., Chen et al..$^{23,25}$ The study area was classified into eight classes, including woodland, arable land (i.e., dry land and paddy field), built-up areas, rural settlements, water body, aquaculture, brine pan and tidal zone. These land-use types and interpretation criteria for Landsat images were used for classifying historical LULC from CORONA image in 1970. The 2005 classification map was directly from the vector data in 2005. The new LULC map for 1990 was generated with the same method as Chen et al. ${ }^{23}$ The samples for supervised classification were selected from pixels without change by comparing the LULC maps before and after 1990, respectively. Using the land-use vector map of the year 2005 as a reference, Landsat TM and SPOT5 images were classified for land use in 2006 and 2011, respectively. The classification accuracies were higher than the standard of $85 \%$ stipulated by the United States Geological Survey classification scheme ${ }^{38}$ For lack of high-resolution data in 1986 and 1995, classification accuracies in these two periods were not quantified.

Here the urban/built-up areas and rural settlements were chosen to generate masks of developed pixels. The nondeveloped areas were reclassified as 0\% impervious surface. Moreover, modified normalized difference water index $(\mathrm{MNDWI})^{39}$ was combined to exclude some rivers ignored in developed areas as follows. Practice has proved that the pixels are regarded as water when satisfying $0.18>$ MNDWI $>0.1$.

$$
\operatorname{MNDWI}=\frac{\left(\rho_{g}-\rho_{m 1}\right)}{\left(\rho_{g}+\rho_{m 1}\right)},
$$

where $\rho_{g}$ and $\rho_{m 1}$ are the apparent reflectance of TM/ETM+ green band (520 to $600 \mathrm{~nm}$ ) and middle-infrared band (1550 to $1750 \mathrm{~nm}$ ), respectively.

\subsection{Accuracy Assessment}

The accuracy assessment involved the following steps. (1) Samples were randomly chosen from the same period's high-resolution data, but excluding the shadow pixels and pixels that are totally different from low-resolution images. (2) Classifications on the sampled pixels of high-resolution images were conducted with integrated methods including visual interpretation, maximum likelihood classification, and vector quantization. The overall accuracy and the kappa coefficient of these classifications on samples should be $>90 \%$ and 0.89 , respectively. (3) All 1-m pixels classified as impervious surfaces were tallied within TM pixels to compute ISA. (4) Accuracy assessment indicators of the mean relative error (MRE) and Pearson correlation coefficient $(R)$ were selected. ${ }^{40,41}$ The overall accuracies of LULC maps for 1990, 2000, 2006, and 2011 were $86.6 \%$ [kappa index (K): 85.1\%], 86.0\% (K: 84.3\%), 86.2\% (K: 84.7\%), and 88.0\% (K: 86.7\%), respectively.

Due to data availability, we evaluated ISA products only for the years of 1990, 2000, 2006, and 2011 by using archived photographs and the Worldview-2 fusion image (Table 3). The accuracies on ISA mapping are listed in Table 3. On the whole, the correlation coefficient is $>0.6$ and MRE is $<15 \%$. There are some uncertainties on these evaluations on the ISA mapping. The different image acquisition time between reference high-resolution images and TM/ETM+ images may show a spectral difference of the same object, which produces the different ISA, though in the same invariant locations. Besides, the assumption that the impervious surface pixels would not return to their pervious surface type at a later time may not be true spanning such a long period.

\section{Results and Discussions}

\subsection{Differences in ISA Changes Among Major Islands}

The percentages of ISA distribution for the entire study area from 1986 to 2011 are shown in Fig. 2. The total ISA in the Zhoushan Islands increased from $19.2 \mathrm{~km}^{2}$ in 1986 to $86.5 \mathrm{~km}^{2}$ in 

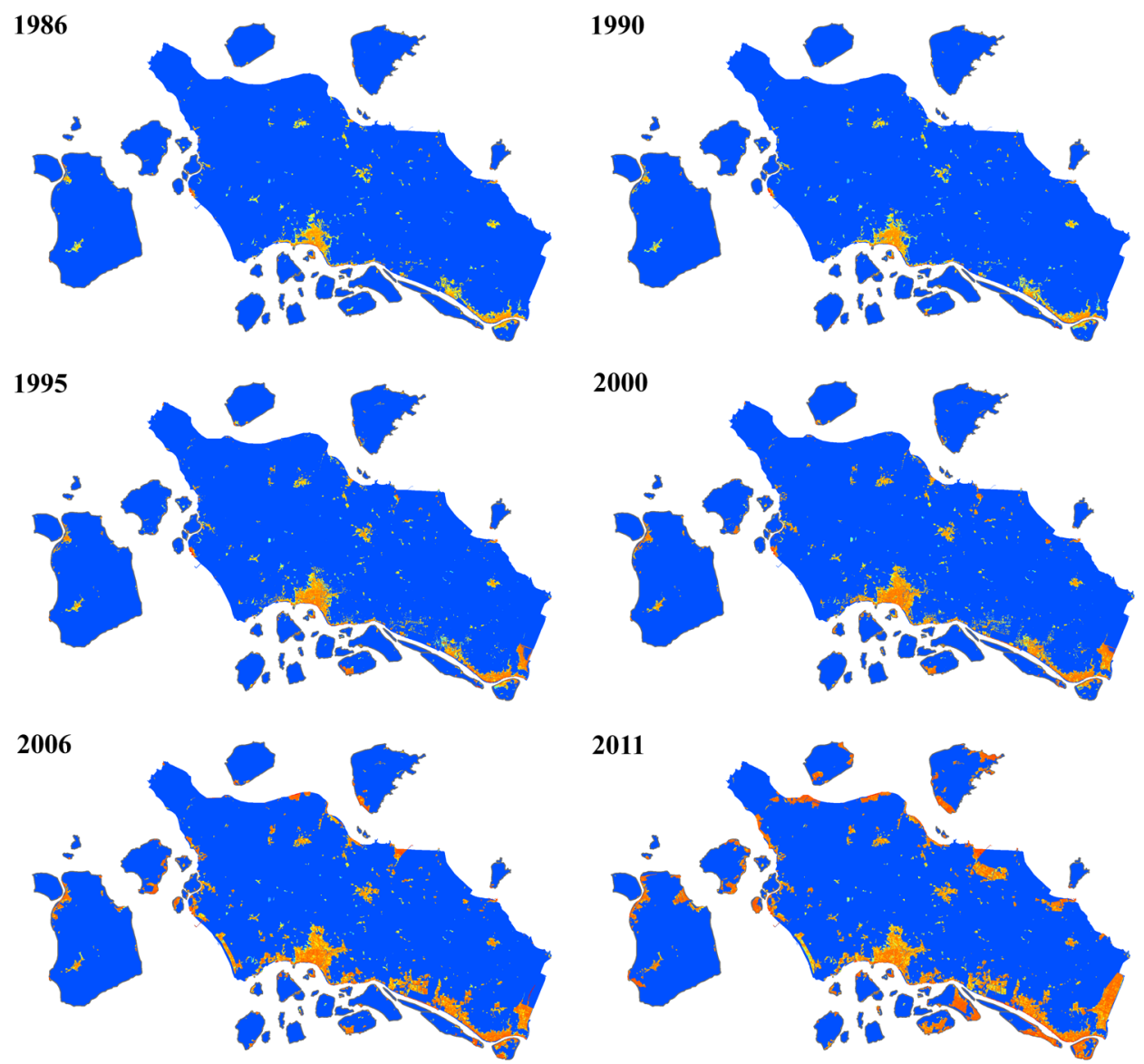

ISA (\%)
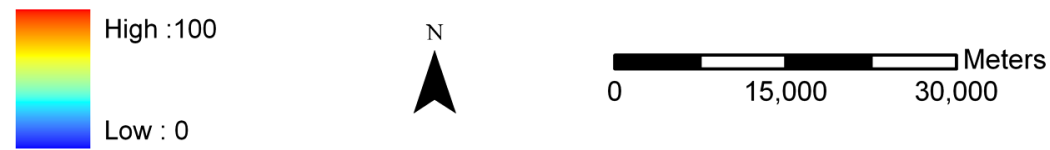

Fig. 2 ISA maps in the Zhoushan Islands, 1986 to 2011.0 to 100 represents the values of ISA (\%).

2011. The growing rate of ISA is continuously increasing during 1986 to 2011 (Fig. 3) and the last period has the highest growing rate of $5.59 \mathrm{~km}^{2}$ per year.

Because of the difference in location, geomorphology, and population among these islands, they have different changes in total ISA and the percentage of ISA. ZS has the largest increase in total ISA, followed by JT, XS, CHZ, CZ, XG, LJZ, PZ, and, DM (Table 4). In terms of change in percentage of ISA, LJZ goes to the first place, followed by CHZ, XG, CZ, XS, PZ, ZS, JT, and DM (Table 4). Islands closer to ZS normally have a larger increase in ISA than farther islands. For example, CHZ, which is $0.3 \mathrm{~km}$ from $\mathrm{ZS}$, has seven times more increase in the percentage of ISA than DM, which has the same size as CHZ but is located far away from ZS. Some smaller islands, such as CHZ, XG, and LJZ, had higher increases in the percentage of ISA than the main island (ZS), even though the policy of "construct the major island and to emigrate from minor islands" was started in 2000. Because of the limited plain area in ZS, the land requirements for industries in this region will fall on nearby islands with ideal landscape and locations.

\subsection{Land Conversions to ISA}

The land-cover change analysis from 1970 to 2011 has been conducted in previous research. ${ }^{25}$ Here we focused on the conversions from other land covers to ISA in the Zhoushan Islands. The LULC maps in the study area from 1986 to 2011 are shown in Fig. 4. The most notable change 


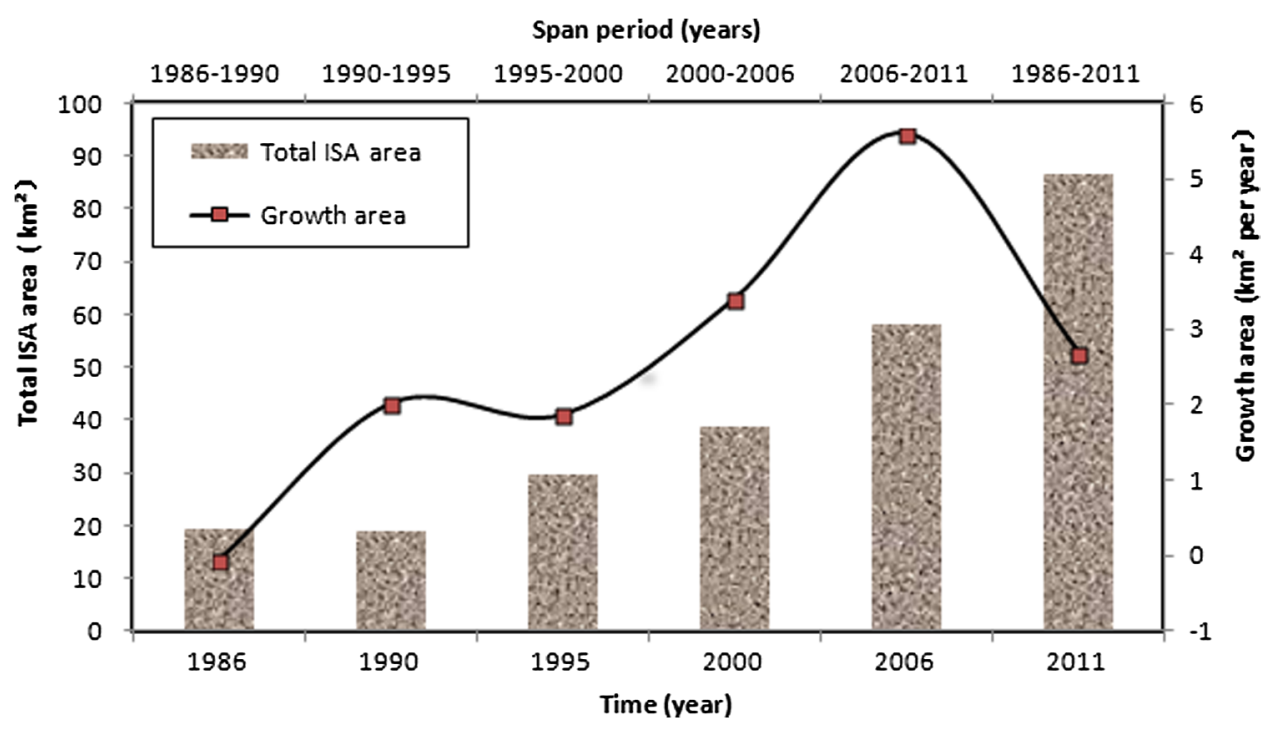

Fig. 3 The total ISA area $\left(\mathrm{km}^{2}\right)$ and growth area $\left(\mathrm{km}^{2}\right.$ per year) for each period.

Table 4 Increased ISA area $\left(\mathrm{km}^{2}\right.$ and area percentage (\%) for each island, 1986 to 2011.

\begin{tabular}{lcrrrrrrrr}
\hline \hline Island & $\mathrm{JT}$ & \multicolumn{1}{c}{$\mathrm{XS}$} & $\mathrm{CZ}$ & $\mathrm{CHZ}$ & $\mathrm{DM}$ & $\mathrm{PZ}$ & $\mathrm{XG}$ & $\mathrm{LJZ}$ & ZS \\
\hline Total area & 4.50 & 3.44 & 2.05 & 2.92 & 0.36 & 0.38 & 1.86 & 1.50 & 44.96 \\
ISA (\%) & 5.55 & 13.53 & 13.66 & 38.86 & 5.50 & 9.06 & 35.59 & 39.88 & 8.92 \\
\hline \hline
\end{tabular}

was built-up areas, which grew by twice the area in 1986, followed by arable land and tidal zone, which shrank by 40.27 and $30.05 \mathrm{~km}^{2}$, respectively. Aquaculture totally increased $10.52 \mathrm{~km}^{2}$, and brine pan decreased $8.57 \mathrm{~km}^{2}$ from 1986. The major land conversions in the Zhoushan islands over the last 25 years were from tidal zone to aquaculture and brine pan, from brine pan to built-up areas and aquaculture, and from arable land to built-up areas. Overall, more and more natural landscapes were disturbed by human activities and the land use had been intensified.

The percentage of ISA was classified into three ranks: 0 to $60 \%, 61$ to $80 \%$, and 81 to $100 \%$. By integrating ISA maps, high-resolution images, and land-use investigation maps, we found that high-percentage ISA (81 to 100\%) mainly covered industrial land, port land, and some urban high-density buildings; middle-percentage ISA (61 to 80\%) involved residential areas outside the city center, hydraulic construction sites, and roads; and low/lower percentage ISA $(<60 \%)$ was composed of green parks and suburban woodlands. During the past 25 years, Zhoushan has experienced a rapid urbanization. The population of urban areas has doubled since $1986 .{ }^{42}$ The increasing population in Dinghai District and Putuo District drove the conversions of natural and arable lands into built-up and urban areas, including infrastructures and facilities, e.g., hospitals, roads, and residential buildings. It generated some new middle-percentage ISA areas in the suburban areas and some new high-percentage ISA areas in the inner city. Besides urbanizations near the big city, there are a growing number of high-percentage ISA areas along the shoreline, e.g., ports, piers, and industrial lands. These were largely converted from tidal zones.

\subsection{Temporal and Spatial Variations in ISA Distribution}

Figure 5 shows that most of the new impervious surfaces were distributed along the coastline of the Zhoushan Islands rather than in the interior from 1986 to 2011. In 1986, impervious surfaces were mainly located in the old cities of Dinghai District, Putuo District, and several designated towns, i.e., Zhanmao, Baiquan, Ma'ao, Cengang in ZS, as well as in Lingang District and the town of Jintang in JT. The period from 1986 to 1990 experienced no big change in ISA. 

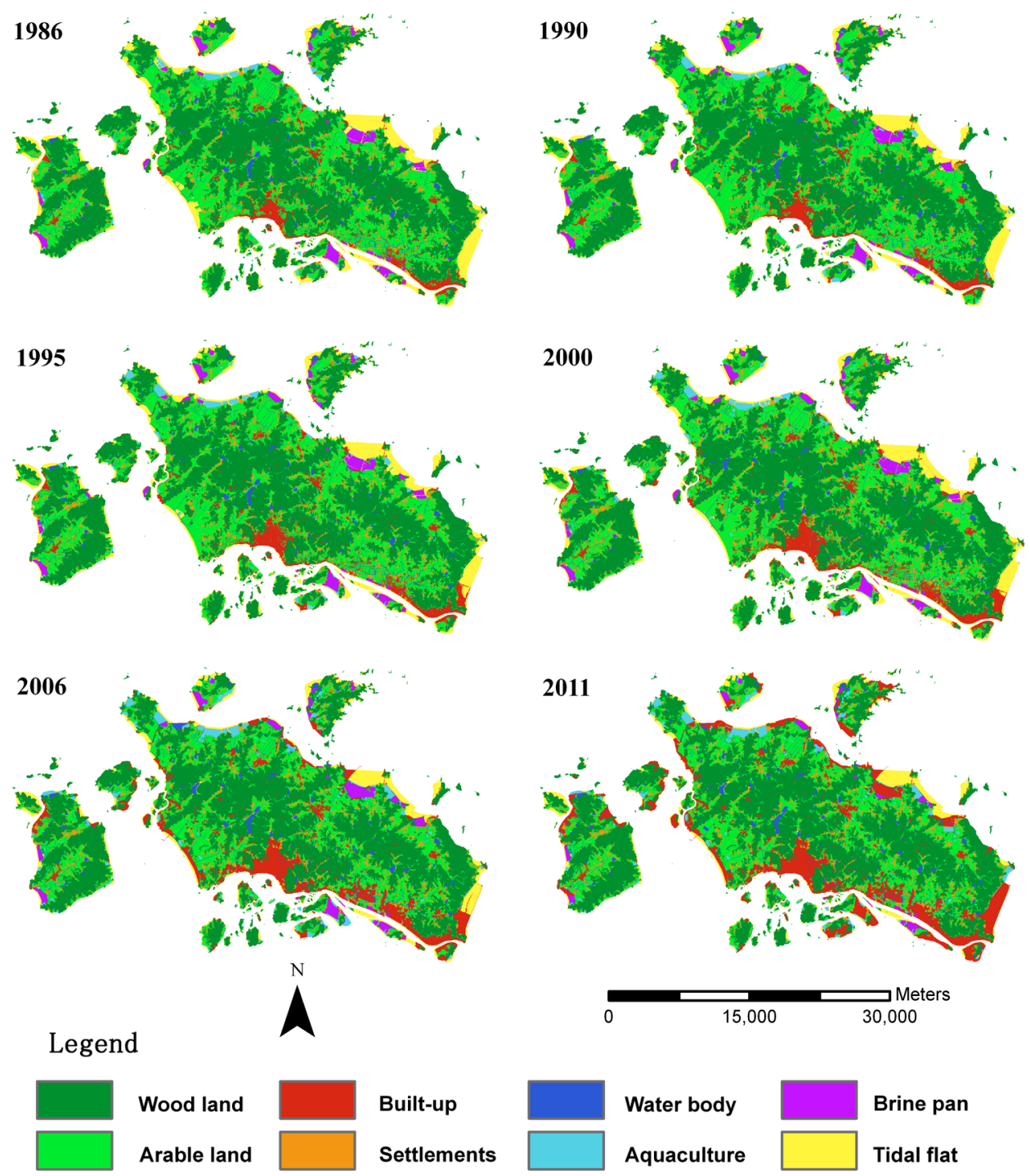

Fig. 4 The LULC maps in Zhoushan Islands, 1986 to 2011.

However, for the periods 1990 to 1995 and 1995 to 2000, large areas of new impervious surfaces formed within and around existing urban areas. After 2000, it was observed that the impervious surface of Dinghai District grew from the inner city to the west and southeast, and gradually merged with the Putuo District. From 2006 to 2011 the impervious surfaces in ZS, XS, CHZ, CZ, and JT islands experienced a rapid growth along the shore. The driving forces of these spatial and temporal patterns of ISA were related to policies and geography. First, the policy that "construct the major island and to emigrate from minor islands" caused the increase in impervious surfaces in ZS from 1990 to 2005. During this period, increasing populations required a growth of infrastructures, including energy, hospitals, roads, subsidized housing, as well as village-owned enterprises in towns. Second, the strategy of "to thrive the city by relying on the port" in 2005 boosted the exploitation of ports, piers, and industrial lands along the shoreline in this region. Finally, the topography also had a certain impact on the distribution of ISA. In ZS, there are hills and mountains in the middle and only small areas of plains distributed in the periphery [Fig. 1(b)]. The plain land existing in the nearby islands gave an expansion chance for Zhoushan urban areas, and therefore, $\mathrm{CHZ}$ and LJZ are functioning as urban extensions of Dinghai District and Putuo District, respectively.

With the expansions of urban area, the frequencies of the percentage of ISA (ISA\%) were changing over time (Fig. 6). Normally, the mean and mode (or the peak) of the ISA\% is becoming higher and higher since the year 1986 (Table 5). 


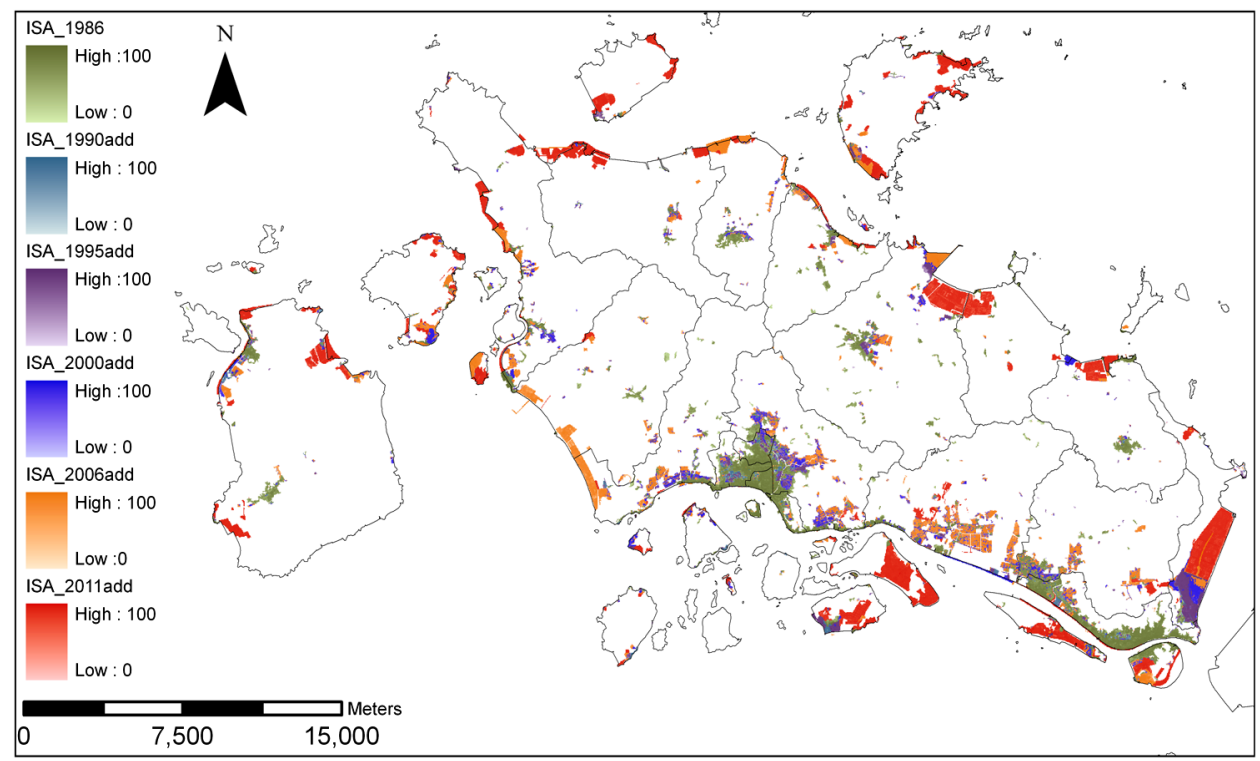

Fig. 5 ISA distribution for the five periods (1986 to 1990, 1990 to 1995,1995 to 2000, 2000 to 2006,2006 to 2011 ) in the new urban areas. The ISA of 1986 was conducted as the reference.

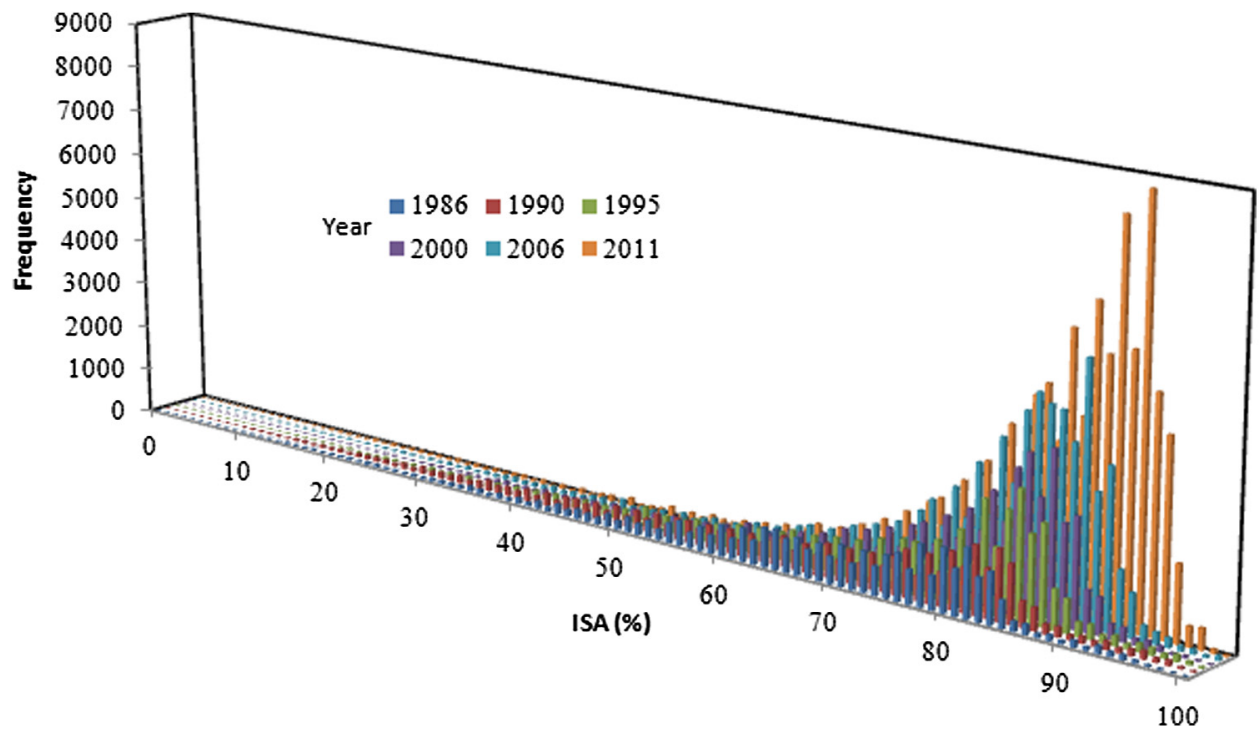

Fig. 6 The frequency distribution of ISA in the increased urban area, 1986 to 2011.

Table 5 The statistical analysis of the percentage of ISA for the increased urban areas from 1986 to 2011.

\begin{tabular}{lcccccc}
\hline \hline Time & 1986 & 1990 & 1995 & 2000 & 2006 & 2011 \\
\hline Mean & $69.04 \%$ & $67.11 \%$ & $74.04 \%$ & $77.72 \%$ & $80.05 \%$ & $82.26 \%$ \\
Mode & $79.89 \%$ & $82.75 \%$ & $84.89 \%$ & $86.11 \%$ & $88.25 \%$ & $91.61 \%$ \\
\hline \hline
\end{tabular}

Note: Mode means the most frequently occurring value. 


\section{Conclusions and Future Works}

This study generated ISA maps of the Zhoushan Islands using multiple satellite data from 1986 to 2011 . These maps show that the total ISAs in the Zhoushan Islands expanded from $19.2 \mathrm{~km}^{2}$ in 1986 to $86.5 \mathrm{~km}^{2}$ in 2011 , at an average increase rate of $2.70 \mathrm{~km}^{2}$ per year. The increasing rate of ISA in these islands had large spatial heterogeneities because of differences in the topography, size, and location. The dominant land conversion in these islands was from tidal zones and arable lands to urban areas with middle and high percentages of ISA. The expansions of ISA occurred unevenly in spatial dimension and most of the new ISA took place in peripheries of these islands. The mean and mode of ISA in urban area increased gradually from 1986 to 2011. The policy and the topography may contribute to the pattern of ISA and its expansions for different periods. Results from this research can be used by policymakers for island management, planning, and for ecological and hydrological modeling to determine the effect of the increasing ISA on coastal environments of the Zhoushan Islands.

Several issues are not covered in this study. One issue is the use of spectral mixture analysis classification approach. Although we have estimated the ISA and its change rate for the Zhoushan Islands from 1986 to 2011, and have captured the general impervious surface dynamic using middle-resolution satellite data, the use of different spectral endmembers for tidal zone, brine pan, aquaculture, and impervious surfaces may improve the classifications on ISA. Another issue is the effects of spatial resolution of remotely sensed data on estimating island ISA. The high-resolution data may better detect the imperviousness of the ring belts, from the central to the urban-rural peripheral, than the Landsat data. ${ }^{26}$ In this study, the 2011 SPOT5/ Worldview-2 data were only used to validate the extraction of impervious surfaces. Highresolution satellites might be used in the near future when they become economically affordable for large-scale mappings.

\section{Acknowledgments}

The authors are grateful to the anonymous reviewers and the editor for insightful comments and valuable suggestions for improving the manuscript. The authors would like to thank Fenglei Fan and Marvin E. Bauer for their help with the calculation of the impervious area. This study was supported by the National Natural Science Foundation of China (Grant Nos. 40976109, 40606040), Zhejiang Provincial Natural Science Foundation of China (Grant No. Y506188), and the R\&D Special Fund for Public Welfare Industry (Oceanography, Grant Nos. 201005011, 201005030).

\section{References}

1. Z. H. Chen, D. L. Pan, and Y. Bai, "Study of coastal water zone ecosystem health in Zhejiang province based on remote sensing data and GIS," Acta Oceanol. Sin. 29(5), 27-34 (2010), http://dx.doi.org/10.1007/s13131-010-0060-9.

2. T. N. Carlson and S. T. Arthur, "The impact of land use-land cover changes due to urbanization on surface microclimate and hydrology: a satellite perspective," Global Planet. Change 25(1-2), 49-65 (2000), http://dx.doi.org/10.1016/S0921-8181(00)00021-7.

3. K. E. Sawaya et al., "Extending satellite remote sensing to local scales: land and water resource monitoring using high-resolution imagery," Rem. Sens. Environ. 88(1-2), 144156 (2003), http://dx.doi.org/10.1016/j.rse.2003.04.006.

4. T. R. Schueler, "The importance of imperviousness," Watershed Protection Techniques 1(3), 100-111 (1994).

5. M. Dougherty et al., "Evaluation of impervious surface estimates in a rapidly urbanizing watershed," Photogramm. Eng. Rem. Sens. 70(11), 1275-1284 (2004).

6. Y. Y. Zhou and Y. Q. Wang, "Extraction of impervious surface areas from high spatial resolution imagery by multiple agent segmentation and classification," Photogramm. Eng. Rem. Sens. 74(7), 857-868 (2008).

7. C. R. Jacobson, "Identification and quantification of the hydrological impacts of imperviousness in urban catchments: a review," J. Environ. Manage. 92(6), 1438-1448 (2011), http://dx.doi.org/10.1016/j.jenvman.2011.01.018. 
Zhang et al.: Using long time series of Landsat data to monitor impervious surface dynamics...

8. Y. B. Deng, F. L. Fan, and R. R. Chen, "Extraction and analysis of impervious surfaces based on a spectral un-mixing method using Pearl River Delta of China Landsat TM/ ETM+ imagery from 1998 to 2008," Sensors 12(2), 1846-1862 (2012), http://dx.doi .org/10.3390/s120201846.

9. R. J. Cermak, A. Feldman, and R. P. Webb, "Hydrologic land use classification using Landsat," in Satellite Hydrology, M. Deutsch, D. R. Wiesnet, and A. Rango, Eds., pp. 262-269, American Water Resources Association, Minneapolis, Minnesota (1979).

10. C. Deguchi and S. Sugio, "Estimation for percentage of impervious area by the use of satellite remote sensing imagery," Water Sci. Technol. 29(1-2), 135-144 (1994).

11. M. E. Hodgson et al., "Synergistic use of Lidar and color aerial photography for mapping urban parcel imperviousness," Photogramm. Eng. Rem. Sens. 69(9), 973-980 (2003).

12. M. K. Ridd, "Exploring a V-I-S (vegetation-impervious surface-soil) model for urban ecosystem analysis through remote sensing: comparative anatomy for cities," Int. J. Rem. Sens. 16(12), 2165-2185 (1995), http://dx.doi.org/10.1080/01431169508954549.

13. C. Wu and A. T. Murray, "Estimating impervious surface distribution by spectral mixture analysis," Rem. Sens. Environ. 84(4), 493-505 (2003), http://dx.doi.org/10.1016/S00344257(02)00136-0.

14. G. Xian, "Satellite remotely-sensed land surface parameters and their climatic effects for three metropolitan regions," Adv. Space Res. 41(11), 1861-1869 (2008), http://dx.doi.org/ 10.1016/j.asr.2007.11.004.

15. L. Wang et al., "Comparison of IKONOS and QuickBird images for mapping mangrove species on the Caribbean coast of Panama," Rem. Sens. Environ. 91(34), 432-440 (2004), http://dx.doi.org/10.1016/j.rse.2004.04.005.

16. R. Brennan and T. L. Webster, "Object-oriented land cover classification of LiDAR derived surfaces," Can. J. Rem. Sens. 32(2), 162-172 (2006), http://dx.doi.org/10.5589/m06-015.

17. X. Hu and Q. Weng, "Impervious surface area extraction from IKONOS imagery using an object-based fuzzy method," Geocarto Int. 26(1), 3-20 (2011), http://dx.doi.org/10.1080/ 10106049.2010 .535616$.

18. H. Q. Xu, "Analysis of impervious surface and its impact on urban heat environment using the normalized difference impervious surface index," Photogramm. Eng. Rem. Sens. 76(5), 557-565 (2010).

19. M. X. Huang et al., "Estimating reclamation level of saline soil using laboratory spectra," J. Remote Sens. (China) 8(4), 378-384 (2004).

20. "Dunhuang Calibration Site of China \& LRCVES/CMA, Spectral Data Sets for Satellite Calibration Site and Typical Earth Objects-Ground Surface with No Vegetation (in Chinese), pp. 259-299, Meteorology Press, Beijing (2008).

21. B. Zhao et al., "An ecosystem service value assessment of land-use change on Chongming island, China," Land Use Policy 21(2), 139-148 (2004), http://dx.doi.org/10.1016/j .landusepol.2003.10.003.

22. F. Bektas and C. Goksel, "Remote sensing and GIS integration for land cover analysis, a case study: Gokceada Island," in 20th Proc. ISPRS, Istanbul (2004).

23. J. Y. Chen, Y. Z. Zhan, and Z. H. Mao, "Land-cover change and its time-series reconstructed using remotely sensed imageries in the Zhoushan islands," Proc. SPIE 7478, 74782B (2009), http://dx.doi.org/10.1117/12.830185.

24. L. Kumar and M. K. Ghosh, "Land cover change detection of Hatiya island, Bangladesh, using remote sensing techniques," J. Appl. Remote Sens. 6(1), 063608 (2012), http://dx.doi .org/10.1117/1.JRS.6.063608.

25. J. Y. Chen et al., "Land-cover reconstruction and change analysis using multi-source remotely sensed imageries in Zhoushan islands since 1970," J. Coastal Res., in press (2013), http://dx.doi.org/10.2112/JCOASTRES-D-13-00027.1.

26. W. F. Li et al., "Effects of spatial resolution of remotely sensed data on estimating urban impervious surfaces," J. Environ. SCI-CHINA 23(8), 1375-1383 (2011), http://dx.doi.org/ 10.1016/S1001-0742(10)60541-4.

27. R. R. Gillies et al., "Effects of urbanization on the aquatic fauna of the Line Creek watershed, Atlanta-a satellite perspective," Rem. Sens. Environ. 86(3), 411-422 (2003), http:// dx.doi.org/10.1016/S0034-4257(03)00082-8. 
Zhang et al.: Using long time series of Landsat data to monitor impervious surface dynamics...

28. M. E. Bauer, B. C. Loffelholz, and B. Wilson, "Estimating and mapping impervious surface area by regression analysis of Landsat imagery," in Remote Sensing of Impervious Surfaces, Q. Weng, Ed., pp. 3-18, CRC Press, Boca Raton, Florida (2007).

29. Q. Weng, "Remote sensing of impervious surfaces in the urban areas: requirements, methods, and trends," Rem. Sens. Environ. 117(2), 34-49 (2012), http://dx.doi.org/10.1016/j.rse .2011.02.030.

30. D. F. Morawitz et al., "Using NDVI to assess vegetative land cover change in central Puget Sound," Environ. Monit. Assess. 114(1-3), 85-106 (2006), http://dx.doi.org/10.1007/ s10661-006-1679-z.

31. Q. Weng and D. Lu, "A sub-pixel analysis of urbanization effect on land surface temperature and its interplay with impervious surface and vegetation coverage in Indianapolis, United States," Int. J. Appl. Earth Obs. 10(1), 68-83 (2008).

32. B. J. Choudhury et al., "Relations between evaporation coefficients and vegetation indices studied by model simulations," Rem. Sens. Environ. 50(1), 1-17 (1994), http://dx.doi.org/10 .1016/0034-4257(94)90090-6.

33. R. R. Gillies et al., "A verification of the 'triangle' method for obtaining surface soil water content and energy fluxes of the normalized difference vegetation index (NDVI) and surface radiant temperature," Int. J. Rem. Sens. 18(15), 3145-3166 (1997), http://dx.doi.org/10 $.1080 / 014311697217026$.

34. T. N. Carlson and D. A. J. Ripley, "On the relationship between NDVI, fractional vegetation cover and leaf area index," Rem. Sens. Environ. 62(3), 241-252 (1997), http://dx.doi.org/10 .1016/S0034-4257(97)00104-1.

35. G. Chander, B. L. Markham, and D. L. Helder, "Summary of current radiometric coefficients for Landsat MSS, TM, ETM+ and EO-1 ALI sensors," Rem. Sens. Environ. 113(5), 893-903 (2009), http://dx.doi.org/10.1016/j.rse.2009.01.007.

36. R. R Gillies, "Growth of impervious surface coverage and aquatic fauna," in Remote Sensing of Impervious Surfaces, Q. Weng, Ed., pp. 387-405, CRC Press, Boca Raton, Florida (2007).

37. R. R. Gillies and T. N. Calson, "Thermal remote sensing of surface soil water content with partial vegetating cover for incorporation into climate models," J. Appl. Meteor. 34(4), 745-756 (1995), http://dx.doi.org/10.1175/1520-0450(1995)034<0745: TRSOSS $>2.0 . \mathrm{CO} ; 2$.

38. J. R. Anderson et al., "A land use and land cover classification system for use with remote sensor data," Geological Survey Professional Paper 964, Government Printing Office, Washington, DC (1976).

39. H. Q. Xu, "Modification of normalised difference water index (MNDWI) to enhance open water features in remotely sensed imagery," Int. J. Rem. Sens. 27(14), 3025-3033 (2006), http://dx.doi.org/10.1080/01431160600589179.

40. L. Yang et al., "Urban land-cover change detection through sub-pixel imperviousness mapping using remotely sensed data," Photogamm. Eng. Rem. Sens. 69(9), 1003-1010 (2003).

41. T. Esch et al., "Large-area assessment of impervious surface based on integrated analysis of single-date Landsat-7 images and geospatial vector data," Rem. Sens. Environ. 113(8), 1678-1690 (2009), http://dx.doi.org/10.1016/j.rse.2009.03.012.

42. Zhoushan Bureau of Statistics of Zhejiang Province, China, "Zhoushan statistical yearbook (1989-2011)," http://www.zstj.net/tjnj/Category.aspx (2013).

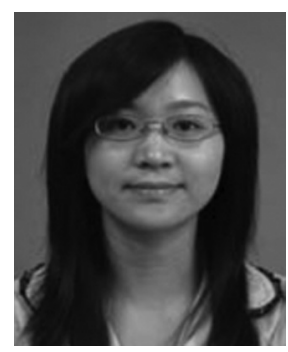

Xiaoping Zhang is a $\mathrm{PhD}$ candidate in earth science from the State Key Laboratory for Information Engineering in Surveying, Mapping and Remote Sensing (LIESMARS), Wuhan University, China. She is currently studying in the State Key Laboratory of Satellite Ocean Environment Dynamics (SOED), Second Institute of Oceanography (SIO), Hangzhou, China. Her research interests include image processing and remote sensing of the coastal environment. 


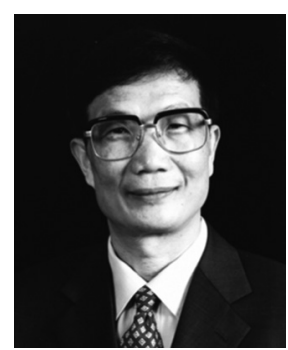

Delu Pan received the BS degree in physics from Nanjing University of Science and Technology, Nanjing, Jiangsu, China. He is currently a senior scientist (Expert of Marine Remote Sensing) of the Second Institute of Oceanography of the State Oceanic Administration (SOA) of the People Republic China, the Academician of Chinese Academy of Engineering and a professor of Zhejiang University, editor-in-chief of Acta Oeanologica Sinica (a journal of the Chinese Society of Oceanography), vice president of the Chinese Society of Oceanography, and a member of the International Ocean-Color Coordinating Group (IOCCG) since 2000.

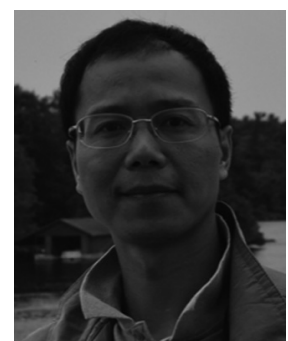

Jianyu Chen received the MSc in environmental science and a $\mathrm{PhD}$ degree in earth science from Zhejiang University, Hangzhou, China, in 1998 and in 2004. He is currently a professor of remote sensing with the State Key Laboratory of Satellite Ocean Environment Dynamics (SOED), Second Institute of Oceanography (SIO), Hangzhou, China. He has been a post doctoral researcher with Shanghai Institute of Technical Physics, Chinese Academy of Sciences. He has also been a visiting professor with the Department of Geography and Environmental Management, University of Waterloo, Waterloo, Ontario, Canada. His research interests include object-based image analysis, remote sensing of coastal environment, and GIS.

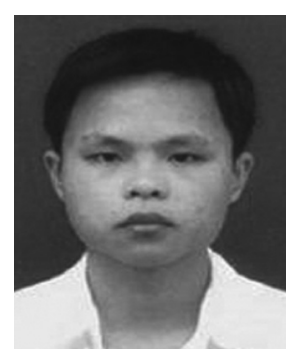

Yuanzeng Zhan received the MSc degree in remote sensing from the Second Institute of Oceanography, Hangzhou, China. Now he is a researcher at Key Laboratory for National Geographic State Monitoring of National Administration of Surveying, Mapping and Geoinformation. His research interests include image analysis, pattern recognition, spatial analysis and remote sensing.

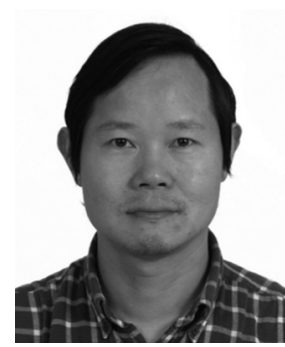

Zhihua Mao received the MSc degree in remote sensing from Zhejiang University, Hangzhou, China, and the PhD in physical electronics from Shanghai Institute of Technical Physics, Shanghai, China. He is currently a vice director of the State Key Laboratory of Satellite Ocean Environment Dynamics, Second Institute of Oceanography, SOA, China, and a professor of earth science, Zhejiang University. His main research interest includes ocean color remote sensing. 